\title{
AC 2009-748: USING CONCEPT-BUILDING CONTEXT MODULES WITH TECHNOLOGY AND 5 E PEDAGOGY TO PROMOTE CONCEPTUAL CHANGE IN MATERIALS SCIENCE
}

\section{Jacquelyn Kelly, Arizona State University}

Jacquelyn Kelley is a M.S. student in the School of Materials in the Fulton School of Engineering at Arizona State University. Her BS degree is in Physics and Chemistry Education. Her principle research areas are inquiry-based learning and development and assessment of inquiry-based modules in materials science and engineering. She teaches physics, chemistry and mathematics in a local arts high school.

\section{James Corkins, Arizona State University}

James Corkins, Arizona State University James Corkins is a Ph.D. student in Science Education, Department of Curriculum and Instruction at ASU. He earned his MS degree in Physics Education at Arizona State University. His BS degree is in Physics. His principle research areas are inquiry-based learning and characterization and measurement of conceptual change in thermodynamics and introductory materials science.

\section{Dale Baker, Arizona State University}

Dale Baker, Arizona State University Dale R. Baker is a Professor of Science Education in the Department of Curriculum and Instruction at ASU and is the Co-Editor of The Journal of Research in Science Teaching. She teaches courses in science curricula, teaching and learning, and assessment courses with an emphasis on constructivist theory and issues of equity. Her research focuses on issues of gende

\section{Amaneh Tasooji, Arizona State University}

Amaneh Tasooji, Arizona State University Amaneh Tasooji is an Associate Research Professor in the School of Materials at ASU and has been teaching and developing new content for materials science and engineering classes and laboratories. She has developed new content and contextual teaching methods from here experience as a researcher and General Manager at Honeywell Inc. She is currently working to develop new assessments to reveal and address student misconceptions in introductory materials engineering classes.

\section{Stephen Krause, Arizona State University}

Stephen Krause, Arizona State University Stephen J. Krause is Professor in the School of Materials in the Fulton School of Engineering at Arizona State University. He teaches in the areas of bridging engineering and education, design and selection of materials, general materials engineering, polymer science, and characterization of materials. His research interests are in innovative education in engineering and K-12 engineering outreach. He has been working on Project Pathways, an NSF supported Math Science Partnership, in developing modules for Physics and Chemistry and also a course on Engineering Capstone Design. He has also co-developed a Materials Concept Inventory for assessing fundamental knowledge of students in introductory materials engineering classes. 


\title{
Using Concept-Building Context Modules with Technology and the 5 E Pedagogy to Promote Conceptual Change in Materials Science
}

\begin{abstract}
Recent advances in technology and pedagogy have demonstrated the potential for improvements in student learning. In this research we are report on the development of prototype teaching and learning modules for an introductory materials science and engineering course. At this time content and activities have been created for modules in two subject areas; atomic bonding and properties and also the area of solutions, solubility, and phase diagrams. Each module is being created as a textbook supplement that uses a technologically-enhanced and contextualized 5E Method (Engage, Explore, Explain, Expand, Evaluate) as the contemporary pedagogy for teaching, learning and assessing the topical content. The 5E Method is supplemented with technology in two ways. First, student class preparation (Engage) uses technology with pre-class, Just-in-Time-Teaching (JiTT) questions which can be web-submitted and will contextualize content with examples from students' everyday lives. This provides a learning bridge from concrete phenomena to the more abstract technical concepts of the content. The JiTT responses are, in effect, a formative evaluation that reveals student learning barriers such as misconceptions and misunderstood definitions. Additionally, students can be engaged (Explore, Explain, and Expand) with in-class Personal Response System Clicker (PRSC) questions. Question responses provide rapid feedback to the instructor and students and can reveal commonly held misconceptions that may hinder learning. The team-based, active-learning 5E pedagogy also utilizes Concept-Building Context Worksheets, which engage students with contextualized multiple representations of topical content that include: visual glossaries; macro/micro illustrations; sample data tables; graphical relationships; and controlling equations. Concept learning has been assessed the Materials Concept Inventory and concept-eliciting tasks that include two-tiered concept questions and concept sketching. The module for solubility, saturation and phase diagrams used content contextualization and concept visualization to promote conceptual change and was well received by a focus group. For a full class of 40 the activities and homework for the bonding module engaged students, improved content understanding, and also revealed unresolved misconceptions. Also, the structure of a module, and especially its concept-building context worksheet, have the potential to lower the barrier to faculty participation in active learning. The research background, construction, use and assessment of modules are described and highlighted with a few examples.
\end{abstract}

\section{Introduction}

In the study of materials science and engineering (MSE) it is found that the behavior of materials is often counterintuitive and, when "novice" learners use everyday experience to create the mental models that comprise their conceptual framework ${ }^{1}$, they may result in misconceptions. These are an individual's scientifically-inaccurate interpretations of the world that can neither explain nor predict phenomena nor properties. A typical example of a faulty mental model resulting in a misconception is "the malleable copper atom" ${ }^{2}$. In the study of materials it is 
important to use effective teaching and learning strategies to promote the kind of conceptual change that repairs students' "commonsense" misconceptions and develops a conceptual framework with deep conceptual understanding and knowledge of materials for use in far transfer of new areas to design and manufacture of contemporary engineering components, devices, and systems.

The emerging understanding of the science of learning is described in How People Learn: Brain, Mind, Experience, and School ${ }^{3}$, which highlights some of the most important findings in the field. One finding, which is about how experts and novices learn and transfer knowledge to new contexts, suggests that, to develop competence, students must develop deep content understanding and need to learn to organize their facts and ideas into a conceptual framework that facilitates retrieval and transfer to new applications. A second is that research on performance of experts and on metacognition indicates that learners can develop their own expertise by defining learning goals and monitoring their progress. A third finding is that students bring their own experience to the classroom as prior knowledge about how the world works. This prior knowledge consists of mental models and associated conceptions (which may or may not be correct) which they have developed from a variety of sources. Such sources might include; earlier classes, textbooks, personal observation, television, and the internet ${ }^{4}$. These prior conceptions may persist during instruction and, if they are incorrect, or applied incorrectly, can act as barriers to learning. The faulty mental models of incorrect prior conceptions are often referred to as misconceptions. The faulty mental models and associated misconceptions are often robust and difficult to displace with scientifically correct mental models. However, effective pedagogy can repair or displace faulty mental models and associated misconceptions by stimulating cognitive processes that achieve conceptual change and alter students' conceptual frameworks. For example, in the important topical area in MSE of dislocations, knowledge and understanding of misconceptions can be assessed with pre-post dislocation-related questions on the Materials Concept Inventory (MCI) ${ }^{5}$, the results of which can then be used to evaluate the effectiveness different of different pedagogical approaches to student learning ${ }^{6}$.

The goal of the work in this research was to develop new, research-based teaching and learning modules about selected topics for introductory materials science courses and then evaluate the modules' effect on change in student conceptual knowledge and understanding for the topics that were addressed. The modules are referred to as Concept-Building Context Modules and use 5E pedagogy integrated with technological feedback. The activities and assessment engage students and give feedback both to students and instructors for more effective learning in the introductory materials science class. One topical area of the modules was on the nature and use of phase diagrams created with a model system of sugar in water. The knowledge could be applied to liquid / solid phase diagrams of important materials systems. The other topical area of a module was on the nature of atomic bonding and its relationship to properties including electrical and thermal conductivity of the three families of materials (metals, ceramics, and polymers) and also the connection between bond strength and properties of melting point, stiffness and coefficient of thermal expansion of materials in the families of materials. The other goal was to document and describe the background, basis, construction and use of the modules for concept building with this construct to active learning such that it would have a general framework that could be applied to other engineering subjects and disciplines. 


\section{Background}

\section{Mental Models and Conceptual Change}

Constructivism espouses the belief that students learn most effectively by constructing their own knowledge and refers to learning as conceptual change ${ }^{7,8}$. How People Learn discusses how cognitive processes act to achieve conceptual change, which occurs through modification of a student's conceptual framework. The framework is comprised of mental models, which are transformed representations of real-world systems or phenomena called modeled target systems or phenomena $a^{9}$. As such, mental models are defined as simplified, conceptual representations that are personalized interpretations of modeled target systems or phenomena in the world around us. Thus, the transformed modeled target systems or phenomena become the mental models which become more visible or comprehensible to the individual ${ }^{10}$. Useful mental models allow us to understand, explain, and predict behavior of systems and phenomena, whereas faulty mental models, which lead to misconceptions, cannot. After revealing and characterizing students' misconceptions, teaching strategies may be devised and tested in order to develop the most effective means of displacing the misconceptions. For example, one effective approach has been shown to be through inquiry learning activities that employ processes such as "cognitive dissonance" which use discrepant events, and by "analogical reasoning" which uses concrete, real-world analogies to bridge to individual understanding of abstract concepts.

As an individual communicates his/her mental models through some form of external representation they are creating their expressed models. These models might take the form of verbal or written descriptions, equations, sketches, diagrams, physical models, computer models or other forms of representation ${ }^{1}$. Thus, expressed models reveal students' "ways of thinking" when elicited by appropriate questions or activities. In fact, when students use a mental model in their conceptual framework and express it in various forms, they are, in effect, explaining their ideas or "modeling a concept". These expressed mental models, or modeled concepts, can be used as indicators to reveal misconceptions and then to track conceptual change as measured by techniques such as the concept inventories, interviews, concept sketches, journaling etc. In this project verbal models are used in pair-discussion and concept sketching was sometimes used with team activities, while the assessment used was multiple-choice questions on the MCI to measure pre-post conceptual change.

\section{Mental Models and Barriers to Conceptual Change - Robust Misconceptions}

Conceptual change is sometimes difficult and may be impeded by robust misconceptions resistant to change because of students' arguments, contradictions, and obstinacy ${ }^{11,12}$. Thus, the general strategies of assimilation or accommodation have been used to promote conceptual change $^{13}$, but for an individual to want to adopt a new concept, it should also be intelligible, plausible, and fruitful ${ }^{14,15}$. The general strategy of assimilation is to build on and modify existing mental models and associated concepts of a conceptual framework. In contrast is accommodation, in which change occurs by major revision or replacement of an existing misconception and associated mental model ${ }^{16}$. One way to do this is with "cognitive dissonance", which occurs when a misconception cannot logically explain new theory, information, or data, nor can it predict phenomena in a reliable way ${ }^{17}$. These general strategies have been 
implemented in specific ways in classroom inquiry activities that include: pair discussions ${ }^{18}$; writing activities and team collaboration ${ }^{19}$; laboratory experiments, team work and vee diagrams $^{20}$; and computer-aided learning ${ }^{21}$.

While some aspects of conceptual knowledge about characteristics of materials at the atomicscale are developed in chemistry and physics courses, other important atomic-scale and microscale structural features of materials related to macroscale phenomena and properties are not presented. To understand the conceptual framework and associated mental models that explain and predict macroscale properties of materials, new content on atomic-scale and microscale structure is introduced in MSE classes. In one sense, the difficulty in developing a fundamental understanding of a material's behavior is an issue of scale. This is because a material's properties are often counterintuitive since they are observed and measured at the macroscale, but can only be explained at the atomic and microscale level. This length scale difference is five to ten orders of magnitude smaller than the scale at which we view properties and phenomena in our lives. As such, informal, "commonsense" mental models ${ }^{22,23}$ are developed in the mind of a "novice learner" which can be scientifically flawed and need to be repaired or replaced by mental models aligned with the scientifically-accepted concepts of consensus models.

In MSE courses major atomic and microscale features of materials are incorporated in mental models as a basis for conceptual understanding of macroscale properties and include atomic bonding, crystal structure (or amorphous lack of structure), defects (both static and dynamicdiffusion), and microstructure (including grains, grain boundaries, grain size, shape, orientation and distribution and also phase size, shape, orientation, and distribution). Atomic-scale features are significantly affected by material composition and processing treatment (thermal, mechanical, electrical, magnetic, etc.) and are used to design and engineer materials to achieve desired properties and performance for given applications. The atomic and microscale features described above strongly affect a material's mechanical properties and need to be incorporated into an individual's mental models and conceptual framework of MSE in order to predict relationships between atomic-scale structure and macroscale properties. For other functional properties, such as electrical, thermal, and optical properties, a material's electronic band structure must also be incorporated into an individual's conceptual framework to explain and predict macroscale properties. Examples will now be presented of faulty mental models and misconceptions that cause incorrect atomic-scale structure / macroscale property relationships.

There are many types of macroscale-property / atomic-scale-structure misconceptions that exist. One is misattribution of macroscopic properties to atomic scale features. For example, copper metal is not malleable because "individual copper atoms are malleable" ${ }^{2}$. Another example related to thermal processing is in explaining why taking a hard, strong copper wire from a hardware store and holding at $600^{\circ} \mathrm{C}$ for 15 minutes makes the copper a softer, weaker material. Although the answer is reduction of dislocation density and recrystallization, a few of the misconceptions proposed by students include; "atomic bonds are weakened" or "atomic bonds are stretched" 22 . The students' misconception is an ontological error in which the misconception is a miscategorized concept. This means, in effect, the explanation related as being due to a thing, in this case atomic bonding, when in reality it is really a process, which is actually the rearrangement of atoms during the annealing process. Another set of misconceptions about 
phases of materials was revealed from the question, "In what phases can nickel exist?" Responses included: "I have never heard of Ni gas", "I have never seen Ni gas", and "I have only seen $\mathrm{Ni}$ as a solid" 23 . The faulty mental models that gave rise to these and other misconceptions originated from various sources individuals use to create "commonsense", novice-learner models that can neither explain nor predict macroscale materials behavior. Some sources include; personal observation, television, textbooks, internet, teachers, and prior classes ${ }^{4}$. To modify a person's conceptual framework of macroscale-property/ atomic-scale-structure relationships, faulty mental models must be revised or replaced by conceptual change to a scientificallyaccepted model.

\section{How Well Do Engineering Students Learn Materials Science and Engineering?}

It was found that students from various disciplines taking introductory MSE courses had typical pre-post conceptual gains for a MCI test ${ }^{24,25}$ of that was typically limited to $7-15 \%$ when content is delivered by lecture-based courses. Responses on MCI questions indicated misconceptions were pervasive $e^{25,26}$, and often related to students' application of inappropriate analogies of macroscale phenomena of everyday life to explain properties of materials really controlled by its atomic-scale structure. In contrast, Hake's ${ }^{27}$ survey of 6000 students in physics courses showed that, using an effective teaching strategy, such as "student engagement", can lead to conceptual gains of $40 \%$ or more as measured by the Force Concept Inventory ${ }^{28}$. This requires mental model modification for conceptual change that promotes a reconstruction of students' flawed conceptual frameworks and can be achieved with effective learning using strategies that can employ a variety of techniques and methods. To succeed in achieving effective learning, faculty in MSE and other engineering disciplines need to understand how their students learn in order to develop effective teaching strategies for improving student knowledge, skills, and motivation. To accomplish this, it is first necessary to characterize students' prior knowledge and misconceptions, and the nature of mental models that comprise their conceptual frameworks. One way is with pre-post tests with the $\mathrm{MCI}^{7}$ which has been used at Arizona State and at some other institutions $^{24,29}$ with Douglas ${ }^{30}$ demonstrating that the MCI is a valid instrument but needed improved reliability. Such assessment can be used to determine what pedagogies most effectively promote conceptual change.

\section{The 5E Method}

In order to achieve effective conceptual development, a complete, consistent, and coherent pedagogy and materials are necessary. Techniques like the 5E Method can be used to ensure students are given ample opportunity to develop ideas into a coherent conceptual framework. The 5E Method provides an outline of essential actions: Engage, Explore, Explain, Expand, and Evaluate. Student understanding can be maximized performed in the outlined sequence.

The first step of the sequence is to engage students. Before students can learn, they must be willing to learn. Here, the instructor can answer the question, "so what?" Students must be engaged such that the content will seem relevant and worth learning. The second component is to allow students to explore. Once relevance is introduced, students should be allowed to explore. Here they are guided to wonder and to start asking questions. Curiosity will drive students to want to know more and to seek further understanding. It is at this point that they will be primed 
for expanding ideas and building their conceptual framework. The next step is to explain. It is in this phase that students are able to encounter new, useful relevant knowledge as well as access prior knowledge and build on it during the introduction of new content which draws students' conceptual framework and mental models. The fourth step of the 5E method is to expand content. This includes applying content knowledge to similar or related situations. Students must use transfer during this phase to show that they can apply content in various ways. This component may often include labs or activities and are the first indication of how the new content has been fit into the student's conceptual framework. Last is the evaluation stage. Evaluations may be done in a various ways including tests, observations, interviews, drawings, and projects. This allows for instructors to assess student understanding and analyze the student knowledge. Together, these five actions outline a sequence necessary for motivating student learning, metacognitively build their knowledge and understanding, and to assess the effectiveness of their ability to transfer their knowledge to a new and different application and setting.

\section{Just in Time Teaching}

One recently-developed teaching method is called Just-in-Time-Teaching (JiTT) which has been used for teaching introductory physics but also for other subjects in science. The JiTT technique is a teaching and learning strategy which has a "feedback loop" that provides student responses of web-based, pre-class study question sets to the instructor who uses them to frame the day's classroom inquiry activities. Students then experience the day's lesson as shaped by their own responses. The pre-class questions target specific content-related issues such as misconceptions, developing concepts, vocabulary, etc. The feedback also provides opportunities to address differences in skills and needs of diverse learners. The components consist of pre-class concept questions, content for informational mini-lectures, follow-on classroom inquiry learning activities, closure, and post-class assessment for example, with homework. Pre-class questions could be configured so responses would open a window on the mental models of students' thinking and understanding. As such, this reveals students' prior knowledge, understanding, misconceptions, reasoning skills and models they use to understand the course content. Desirable learning skills can be promoted through appropriate shaping of pre-class questions. Such skills would include those described by How People Learn such as developing metacognition to facilitate skills like concept organization and relationships and monitoring learning progress. Thus, the use of JiTT in modules reveals prior knowledge, monitors student understanding, enhances learning skills, and promotes learning of MSE content through conceptual change.

\section{Concepts in Context}

A major goal of the mathematics, science, and engineering science courses taken by engineering students is to provide a conceptual foundation of knowledge and processes that can be applied to their own disciplinary engineering content and applications. This requires the student learner to have the ability to take the conceptual knowledge of a subject from the context of math, science, or engineering science learning and transfer it to the context of engineering design and problem solving in their own discipline. When learners have the ability to accomplish this, the book, How People Learn ${ }^{1}$, describes them as having, or developing, deep conceptual knowledge. This is also characteristic of an individual who is becoming, or has become, an "expert" in an area of 
conceptual knowledge. Contextualized concepts promote this type of learning. This is in contrast to the shallow conceptual knowledge of a "novice" who lacks the ability to transfer his/her knowledge to new and different contexts other than the one in which the knowledge was acquired. This ability to transfer knowledge is also an indicator that effective conceptual change has occurred and has stabilized ${ }^{1}$.

\section{Methods}

\section{Development of Modules}

The development of materials for the modules about solubility and solutions and for bonding for this study followed the general principles and guidelines of the 5E Method as described above. The components of the 5E pedagogy are listed below

Engage - JiTT questions and introductory slides (context, elicit, multiple representations) Explore - Briefly introduce Concept-Building Context Worksheet of real-world applications (relevance, wonder, curiosity) - students familiarize with content but need more information Explain - Mini-lecture (visual, verbal, mathematical, graphical representations of content) provides students with necessary information to solve real-world problems in matching activity Expand - Concept-Building Context Worksheet - Students negotiate content meaning and definition with other team members for best matching of choices - real-world connections between structure, properties, and processing are illustrated- the key concept in materials science Evaluate - Open-ended homework questions - to indicate how well concepts are grasped

In the material created for the modules, each concept is shown in an engineering and real-world context with a given material for a given application. This allows students to understand the significance and application of concepts that might otherwise be difficult or may seem trivial. Because there is clear relevance, student motivation and engagement increase. Additionally, this contextualization with authentic, real-world objects allows students to connect prior knowledge and experience to expand their own conceptual framework rather than try to link isolated facts.

\section{Measuring Learning and Conceptual Change}

An appropriate instrument is necessary to quantitatively measure conceptual understanding (and complement qualitative studies of student responses) and associated conceptual change of MSE students. For introductory MSE classes an instrument called the Materials Concept Inventory (MCI) has been developed to measure conceptual gain. It has been used for pre-post tests at ASU and a few universities with good preliminary results in measuring conceptual change resulting from a MSE class. However, concept inventories, such as the MCI, are usually used for summative evaluation as pre-post course tests. To complement this information with formative assessment and to monitor and understand progression in conceptual change, formative evaluation tools that could be used include: JiTT questions, clicker questions, homework questions, and two-tiered classroom questions. Such questions would be developed for each topical area during the progress of the course. In two-tiered questions in which the first tier is a set multiple choices containing the correct answer and distracters and the second tier is an open- 
ended request for an explanation for the first tier choice. This technique is especially effective in to determine the origins of materials misconceptions.

\section{Bonding Module}

Materials being developed for the bonding module were administered to one section of an introductory materials science and engineering class with 40 students who were primarily mechanical engineering students. Others were from bioengineering, chemical engineering, industrial engineering, and materials engineering. The MCI was given in the first week of a 15week semester which was before the topic of bonding was discussed. The materials for the module were used over two 75 minute class periods. The classes followed the 5E pedagogy with students engaging in a brief hands-on activity comparing stiffnesses of different metals to highlight the role of differences in bonding. Next, students spent a short amount of time (4-8 minutes) exploring the Concept-Building Context Worksheet (see Appendix 1) that requires students to match real-world applications with underlying atomic level features in order to illustrate structure property relationships for bond strength. Next, for the explain phase of 5E, with students now somewhat familiarized with content, a short informal mini-lecture was delivered to provide students with the necessary information about bonding-property relationships and underlying principles so they could, in the expand phase, solve real-world matching activity problems. With the new knowledge from the explain phase, teams of 3-5 students then worked on the expand phase with the Worksheet, with each team completing one matching problem. All students were engaged as the faculty member walked around the room and discussed some content with each of nine teams. This approach provides a very easy way to engage faculty in active learning without having the training and apprenticeship usually required to develop and/or teach active learning materials. Each of the nine teams reported out at the front of class to inform the other teams. Students then completed the $5 \mathrm{E}$ cycle with the last component, the evaluate phase, when they were then assigned a Concept-Building Homework, an example of which is shown in Appendix 1. Thus, the students had the opportunity with that homework to apply their knowledge in a new setting which allowed assessment of conceptual development and change and also revealed remaining misconceptions.

\section{Solubility, Saturation, and Phase Diagrams Module}

The solubility, saturation and phase diagrams module was administered to a small focus group. The focus group consisted of three students. A series of questions on solubility, saturation, and phase diagrams were administered during the first session. Students were given twenty minutes and asked to turn in tests anonymously. Students were interviewed in order to gain clearer insight on why answers were chosen to each question. The modules were then presented over two 75 minute sessions. The post test was administered during the fourth session. As before, students were given twenty minutes to respond to the questions and interviewed upon completion to explain the reasoning in each of their choices.

\section{Results and Discussion}

In the focus group, students expressed appreciation for contextualized examples and content. Open-ended questions promoted understanding by student thinking. Answers revealed prior 
knowledge and content comprehension. In the bonding module, students were able to show their thinking through the Concept-Building Context Worksheet. In these, they were able to pick between a selections of predetermined choices to find the most appropriate answer for each choice. Students showed their reasoning throughout the selection process. This allowed for them to use pieces of their prior knowledge. It forced students to correctly categorize these pieces, contextualize ideas, and make connections between properties, processing, and structure of various materials. As students engaged in this process, their thinking and ideas were made apparent. Their reasoning was mapped as students chose, revised, and settled on their choices to each question. For example, on the Concept-Building Context Worksheet in Appendix 1, the student had originally chosen that a metal trash can have covalent and van der Walls forces as the core of its atomic structure. Here, it is clear that the student did not previously draw a connection between material and type of bonding. As shown, the student's mind was changed as a result of team work. Afterwards, correctly choosing metallic bonding as the structure responsible for the metal trash can. This reorganization was apparent throughout the remainder of the worksheet as well and clearly reflects the change from the initial multiple disconnects between the macroscopic and the atomic level to the beginning of establishing consistent model.

The class structure involved short mini-lectures followed by individual concept exploration, team work, and team presentation to class. Students responded positively to team work as they appeared more engaged, academically driven, and inquisitive. By working in a small team, students were forced to negotiate ideas. This allowed for students to discuss and debate their ideas and come to a team consensus. The articulation of thoughts aided in student conceptual understanding. As students feel the need to defend their choices to peers, they are required to explain ideas completely. In doing so, any logical inconsistencies in conceptual frameworks and mental models are revealed. Because the team is working together to come up with a reasonable model, when a faulty model is presented, an alternative one is often suggested immediately by other team members. This process of cognitive dissonance and alternative conceptions hinted at student conceptual change during completion of the activity.

The homework allowed for students to answer open-ended questions relating to the connection between material structures, properties, and processing. It proved useful as an assessment for student understanding of content introduced in the previous lesson. The homework included why specific materials were chosen for distinct applications. Identification of common objects probed students to identify how they were processed and their relevance in the engineering community. This allowed students to begin observing common objects from engineering, as well as materials science lenses.

For material in the solubility and saturation module, emphasis was placed on the use of multiple representations. Students were commonly exposed to and asked to explain reasoning through visual, graphical, mathematical, diagrammatical, verbal, and written representations. In doing so, students' coherent conceptual frameworks were revealed. When students were asked to explain concepts, often they gave explanations that seemed reasonable and consistent with normative views. However, when asked to use an alternative mode of explanation, like a graph, it was often apparent that there were misunderstandings in their mental models. This made for easier diagnosis of misconceptions which allowed for more individualized and effective instruction. Student interviews showed an improvement in conceptual understanding on concepts pertaining 
to solubility and saturation. Though improvement was shown in answers to questions about phase diagrams, student interviews showed a lack of understanding in the use of phase diagrams.

\section{Summary and Conclusions}

A different approach for achieving conceptual change in materials science has been described. By using the 5E pedagogy integrated with real-world contextualized applications and technology, students are able to explore content in a way that builds brides between their everyday experience and the abstract conceptual knowledge that instructors desire students to learn. This encourages drawing connections between materials, their properties, their processing, and their selection. The team work and content negotiation mimics design teams and processes that occur in engineering careers after graduation. Expression of content knowledge in multiple representations allows for students to evaluate the fidelity of their mental model with respect to the consensus model as well as revealing any possible inconsistencies and associated misconceptions in their mental model of a concept. By addressing and repairing misconceptions in foundational content areas, such as bonding and solutions and solubility, students will be more able to learn and understand complex topics such as dislocations, solid state diffusion, phase diagrams and microstructures.

\section{Acknowledgement}

The authors acknowledge the support of this work from NSF CCLI Grant \#0737146.

\section{Bibliography}

1. Boulter, C. J., \& Buckley, B. C. (2000). Constructing a typology of models in science education, in Gilbert, J. K., \& Boulter, C. J. (Eds.), Developing models in science education. Dordrecht, Netherlands, Kluwer Academic Publishers.

2. Ben-Zvi, R., Eylon, B., \& Silverstein, J. (1986). Is an atom of copper malleable? Journal of Chemical Education, 63, 64-66.

3. Donovan, M. S., Bransford, J. D. \& Pellegrino, J. W. (Eds.) (1999). How People Learn: Bridging research and Practice. National Academy Press, Washington, DC.

4. Kikas, E. (2004). Teachers' conceptions and misconceptions concerning natural phenomena. Journal of Research in Science Teaching, 41(5) 432-448.

5. Krause, S., Decker, J., Niska, J., \& Alford, T. (2002). A Materials Concept Inventory for introductory materials engineering courses, National Educators Workshop Update 2002, 17, 1-8.

6. Krause, S., Decker, J. C., \& Griffin, R. (2003). Using a Materials Concept Inventory to assess conceptual gain in introductory materials engineering courses. 2003 Frontiers in Education Conference Proceedings, Savannah, GA.

7. Vygotsky, L. (1962) Thought and Language, T. E. Hanfmann \& G. Vaka (Eds.), Cambridge, MA: MIT Press.

8. Von Glaserfield, E. (1987). The Construction of Knowledge: Contributions of Conceptual Semantics (Seaside, CA: Intersystems Publications, Inc.).

9. Norman, D. (1983) Some observations on mental models. In Mental Models, D. Gentner and A. Stevens (Eds.), Hillsdale, NJ, Erlbaum. 
10. Gilbert, J. (1995) The role of models and modeling in some narratives in science learning. 1995 Annual Meeting of the American Educational Research Association, San Francisco, CA.

11. Niaz, M. (2005). How to facilitate students' conceptual understanding of chemistry? - A historical and philosophy of science perspective. Chemical Education International, 6(1), 1-5.

12. Vosniadou, S. and Brewer, W. F. (1992) Mental models of the earth: A study of conceptual change in childhood. Cognitive Psychology, 24, 535-585.

13. Dykstra, D. I., Boyle, C. F., \& Monarch, I. A. (1992). Studying conceptual change in learning physics. Science Education, 76(6), 615-652.

14. Posner, G. J., Strike, K. A., Hewson, P. W., \& Gertzog, W. A. (1982). Accommodation of a scientific conception: Toward a theory of conceptual change. Science Education, 66(2), 211-227.

15. Hewson, P. W. (1996). Teaching for conceptual change. In Improving teaching and learning in science and mathematics. D. F. Treagust, R. Duit, \& B. J. Fraser (Eds.), New York, NY: Teachers College Press, Columbia University.

16. Lakoff, G. (1993). The contemporary theory of metaphor. Metaphor and thought 2nd ed., In A. Ortony (Ed.), New York, NY, Cambridge University Press.

17. Chinn, C. A., \& Brewer, W. F. (1993). The role of anomalous data in knowledge acquisition: A theoretical framework and implications for science education. Review of Educational Res., 63, 1-49.

18. Kobayashi, Y. (1994). Conceptual acquisition and change through social interaction. Human Development, $37,233-241$.

19. Fellows, N. (1994). A window into thinking: using student writing to understand conceptual change in science learning. Journal of Research in Science Teaching, 31, 985-1001.

20. Ebenezer, J. V., \& Gaskell, P. J. (1995). Relational conceptual change in solution chemistry. Science Education, 79, 1-17.

21. Biemans, H. J. A., \& Simons, P. R.-J. (1995). Computer-assisted instruction and conceptual change. 1995 Annual Meeting of the American Educational Research Assoc., San Francisco, CA.

21. Nieswandt, M. (2001). Problems and possibilities for learning in an introductory chemistry course from the perspective of conceptual change. Science Education, 85,158-179.

22. Chi, M.T.H. (1992). Conceptual change within and across ontological categories: Examples from learning and discovery in science. In R. Giere (Ed.), Cognitive models of science ( pp.129-186). Minneapolis, MN: Minnesota Press.

23. Krause, S. Tasooji, A., \& Griffin, R. (2004). Origins of misconceptions in a Materials Concept Inventory from student focus groups. 2004 ASEE Annual Conference and Exposition Proceedings, Salt Lake City, UT.

24. Jordan, W., Cardenas, H, and O' Neal, C. B. (2005). Using a Materials Concept Inventory to Assess an Introductory Materials Class: Potential and Problems. 2005 ASEE Annual Conference and Exposition Proceedings, Portland, OR.

25. Krause, S., Decker, J., Niska, J., \& Alford, T., \& Griffin, R. (2003). Identifying student misconceptions in introductory materials engineering courses. 2003 ASEE Annual Conference Proceedings, 732-740

26. Krause, S., and Tasooji, A., (2007). Diagnosing Students' Misconceptions on Solubility and Saturation for Understanding of Phase Diagrams, 2007 American Society for Engineering Education Annual Conference Proceedings, Honolulu, HI.

27. Hake, R.R. (1998). Interactive-engagement versus traditional methods: A six-thousand survey of mechanics test data for introductory physics courses. American Journal of Physics, 66(1), 64-74.

28. Hestenes, D., Wells, M., \& Swackhamer, G. (1992). Force concept inventory. The Physics Teacher, 30(3), $141-151$. 
29. Gleixner, S. H., Douglas, E., \& Graeve, O. (2006) Project-based introductory to materials engineering modules on biomaterials, solid oxide fuel cells, non-volatile memory, and fiber reinforced plastics. 2006 ASEE Annual Conference and Exposition Proceedings, Chicago, IL.

30. Douglas, E. (2007) Effects of sex and ethnicity on performance on the Materials Concept Inventory. 2007 ASEE Annual Conference and Exposition Proceedings, Honolulu, Hawaii. on CD.

31. Song, S., and Agogino, A.M., (2004) An analysis of designers' sketching activities in new product design teams, Proceedings, 2004 ASME Design Theory and Methodology Conference, American Society of Mechanical Engineers, Salt Lake City, Utah.

32. Schutze, M., Sachse, P., and Romer, A., (2003) Support value of sketching in the design process. Research in Engineering Design, Vol. 14, 89-97.

33. Lowe, R., (1993). Constructing a mental representation from an abstract technical diagram. Learning and Instruction, v. 3, 157-179.

34. Johnson, Julia K. and Reynolds, Stephen J., (2005). Concept sketches - using student-and instructor-generated annotated sketches for learning, teaching, and assessment in geology courses. Journal of Geoscience Education, v.52, 85-95.

35. Pearce H. T. \& P. le Roux. 2000. "The Force Concept Inventory: its meaning for teaching physics," in Proceedings of the 2nd Southern African Conference on Engineering Education, Vanderbylpark, South Africa, 219-224. 
Appendix 1 - Concept Building Context Worksheet and Homework
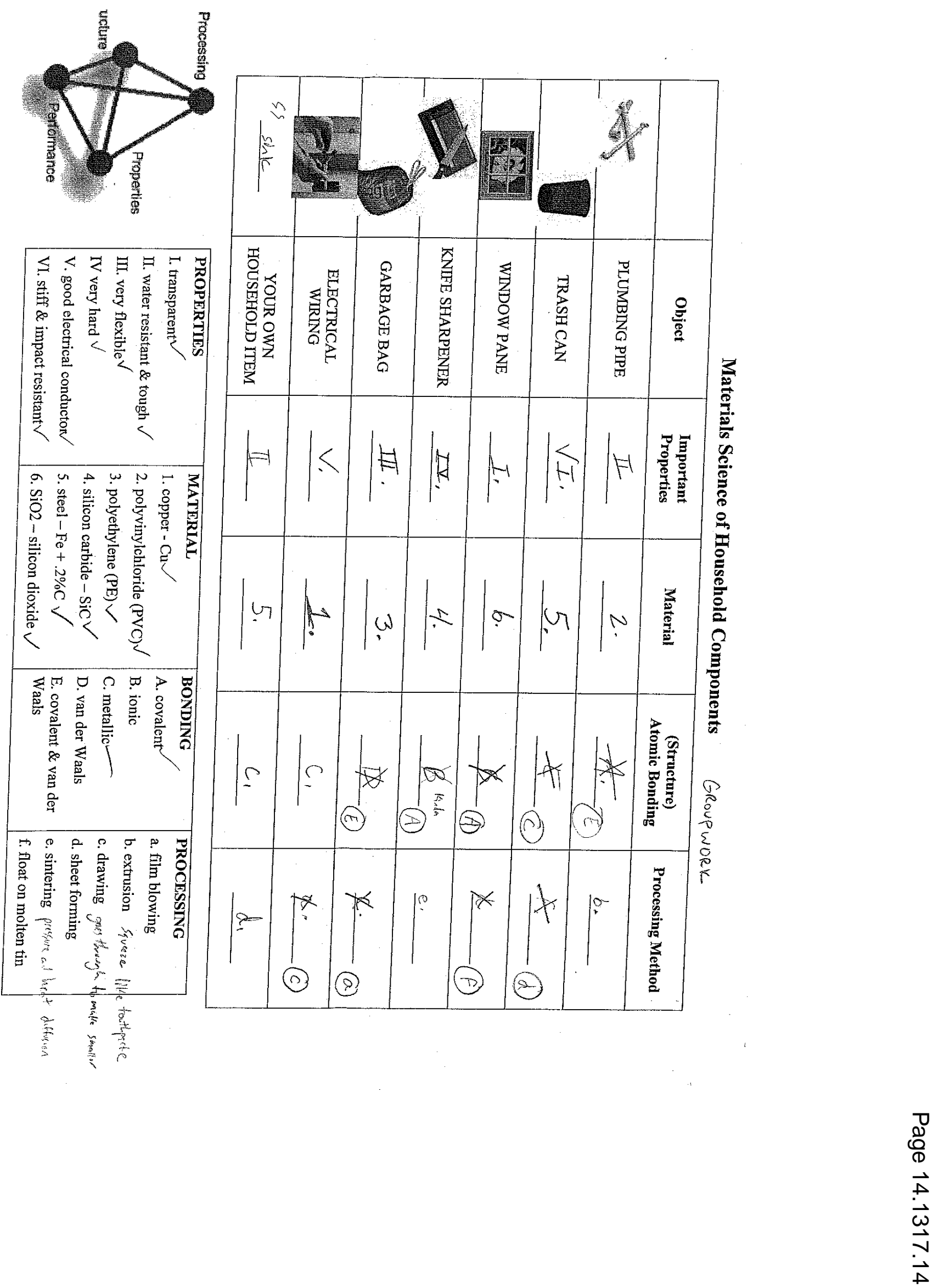

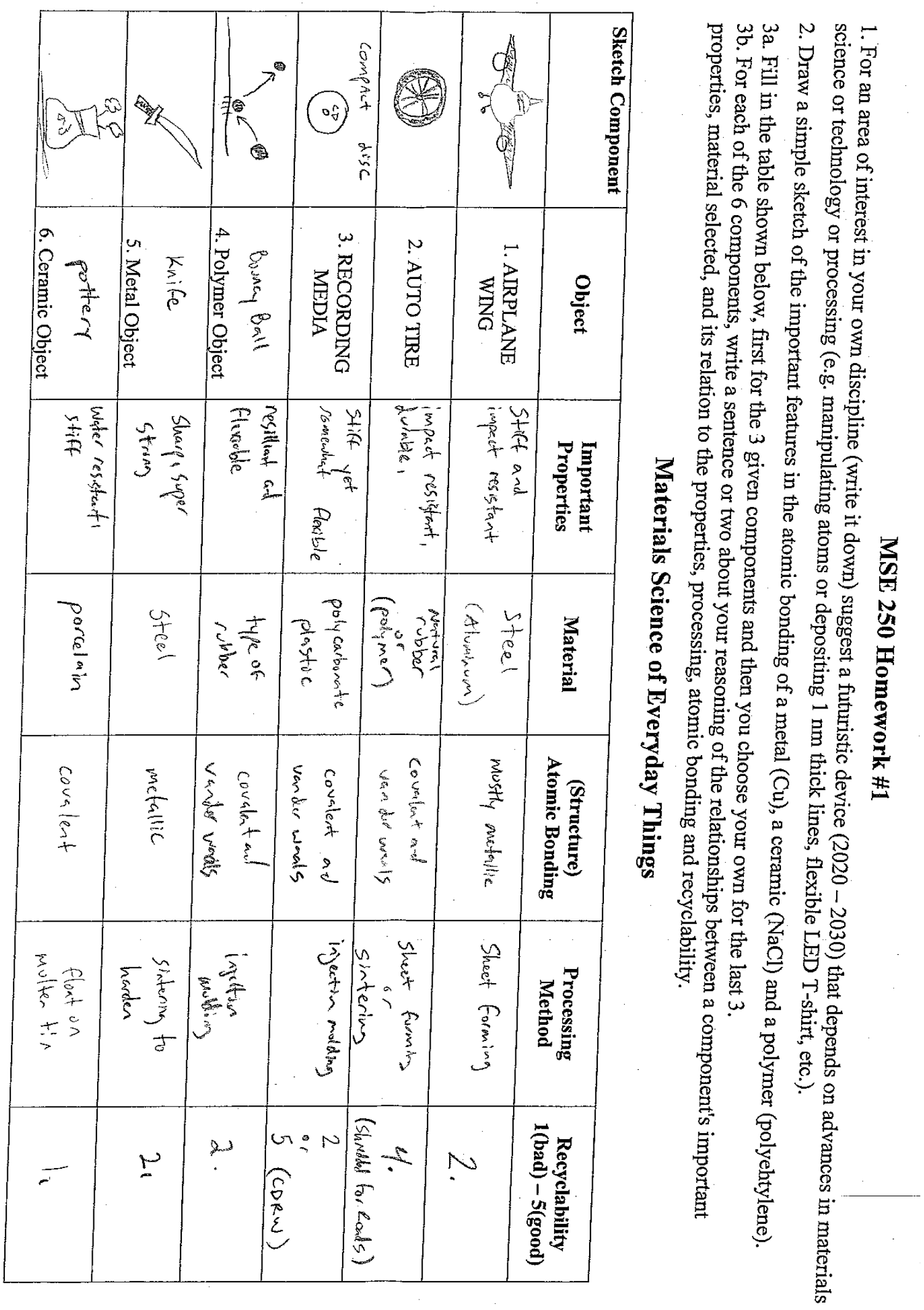